\title{
Editorial
}

\section{Remote Sensing of Aerosols}

\author{
Francisco Molero $\mathbb{D}$
}

Atmospheric Pollution Unit, CIEMAT. Avda Complutense, 40., 28040 Madrid, Spain; f.Molero@ciemat.es

Received: 15 October 2019; Accepted: 25 October 2019; Published: 28 October 2019

Aerosols play an important role in the radiative balance of the Earth climate system. Nowadays, a large uncertainty is assigned to the indirect effect of aerosols, related to their interaction with clouds. This is mainly due to the highly variable aerosol properties in space and time. Recent developments in remote sensing and coordination of ground-based instruments as networks, such as Aerosol Robotics NETwork (AERONET), have allowed a better characterization of aerosols at a global scale. In this special issue, nine original articles show new recent developments in remote sensing techniques [1-5] and synergies derived from combined use of different techniques [6-9].

For instance, Wang et al. [1] investigated representative meteorological situations over Vipava valley (Slovenia) by means of a two-wavelength polarization Raman LiDAR. They observed Kelvin-Helmholtz instability above the valley, at the height of the adjacent mountain ridge, and new evidence for Bora-induced processes which inject soil dust aerosols into the free troposphere up to twice the height of the planetary boundary layer. From the observed stratified vertical aerosol structure and specific optical properties of different layers, they identified predominant aerosol types in these layers. Also using lidar systems, Rosu et al. [2] developed a semi-empirical model, which utilizes data gathered with a standard biaxial elastic lidar platform, in order to calculate the altitude profiles of turbulence parameters. Additionally, the model can be used to calculate the Planetary Boundary Layer height. Also, Zo and Shin [3] correlate the spectral linear particle depolarization ratios with the aerosol type. Employing data from AERONET, they found that the AERONET-derived particle depolarization ratios were generally within the range of those provided by lidar observations for each aerosol type: dust, polluted dust, smoke, non-absorbing, moderately-absorbing and high-absorbing pollution, advancing in the identification and classification of aerosol types using remote sensing techniques. Also related with AERONET products, Zheng et al. [4] investigates the feasibility of retrieving the aerosol fine-mode fraction from ground-based sky light measurements. An inversion algorithm, based on the optimal estimation theory, is presented to retrieve Fine Mode Fraction from single-viewing multi-spectral radiance measurements and to evaluate the impact of utilization of near-infrared measurements at a wavelength of $1610 \mathrm{~nm}$ in aerosol remote sensing. The proposed algorithm was employed on real data taken during a haze pollution event in Beijing. The correlation coefficients for the retrieved aerosol volume fine-mode fraction and optical fine-mode fraction against AERONET products were 0.94 and 0.95 respectively, and the mean residual error was $4.95 \%$. These results confirm the high value of Near InfraRed measurements for the retrieval of coarse mode aerosols. Finally, Xu et al. [5] improved the merged AOD performance by introducing a new regression method applied to the moderate resolution and imaging spectroradiometer (MODIS). Level 2 operational aerosol products are based on the dark target (DT) method over vegetated regions and the enhanced deep blue (DB) algorithms over bright pixels. However, increasing the data coverage by merging the DT and DB merged AOD product has recently become the focus of research. This study aims to improve the merged AOD performance by introducing a new regression method (DTBRG), depending on the normalized difference vegetation index values when DT and DB AOD are valid. The inter-comparison of merged AOD550s from different methods with an equal number of coincident observations demonstrates that the DTBRG method performs better than the MODIS official algorithm with increased expected error $(83 \%$ versus 
$76 \%), R(0.92$ versus 0.90$)$, and decreased bias ( -0.001 versus 0.012$)$. Therefore, it can be operationally used for global merged aerosol retrievals.

Other works are related to synergies obtained by combined different instruments, for instance, De Oliveria et al. [6] employed four different remote sensing datasets: the Moderate Resolution Imaging Spectroradiometer (MODIS), the Aerosol Robotic Network (AERONET), the Cloud-Aerosol LIDAR with Orthogonal Polarization (CALIOP) and a ground-based Lidar from Natal. They performed a 12-year analysis, from 2005 to 2016, over Brazil, evaluating and identifying distinct aerosol types by means of Aerosol Optical Depth (AOD) and Angström Exponent (AE). Aerosol types were identified as sea spray, biomass burning, and dust aerosols mostly transported from tropical Africa, mainly in low aerosol scenarios with AOD values from 0.04 to 0.52. Chilinski et al. [7] compared absorption coefficient and SSA measurements performed with on-ground in-situ devices (aethalomter, nephelometer), small unmanned aerial system (UAS) carrying micro-aethalometer, as well as with lidar/ceilometer. The study took place in Strzyżów (South-East Poland, Eastern Europe) and a weak correlation was observed between columnar SSA and ground SSA, which were mainly explained by hygroscopic effects, increasing scattering coefficient in ambient (wet conditions), and partly high uncertainty of SSA retrieval. AAOD derived with the use of profiles from UAS up to PBL height, was estimated to contribute in average to $37 \%$ of the total AAOD. A method of AAOD estimation, in the whole troposphere, with use of measured vertical profiles of absorption coefficient and extinction coefficient profiles from lidars was proposed. Measurements of SSA from drones agree well with ground measurements and are lower than results from AERONET, which suggests a larger contribution of absorbing aerosols. Zhang et al. [8] analyzed a haze event over Nanjing (China) using ground-based and spaceborne sensors, combined with sounding and HYSPLIT backward trajectory data. Ground-based and spaceborne sensor data exhibited good consistency. The afternoon convection caused the aerosol uplift during the haze event with pollutants at high altitude dominated by small particles, while the overall pollutant mix was dominated by mixed aerosols. Near-surface inversion layers stopped pollutant dispersal, with only very stable ocean air mass transport in the southeast direction available. Finally, Roshan et al. [9] have performed a comprehensive quantification of the long-term variability of aerosol species over the Arabian Peninsula. In this study, the speciation, variability, and distribution of aerosol optical depth over the Arabian Peninsula during 2005-2015 is analyzed by using the modern-era retrospective analysis for research and applications, Version 2 (MERRA-2) model together with satellite retrieved data and AERONET observations. An increase in AOT values between 2005 and 2009 is attributed to increased dust generation from the Sahel region in Northern Africa, and the Fertile Crescent (Syria, Iraq, Jordan) due to an extended dry period.

In summary, this issue makes an important and broad contribution to the field of remote sensing of aerosols. We are very thankful to our colleagues for their invaluable contributions and the reviewers for constructive comments and suggestions that helped to improve the papers. We thank the editing office for their excellent support in processing and publishing this issue.

Conflicts of Interest: The author declares no conflict of interest.

\section{References}

1. Wang, L.; Stanič, S.; Eichinger, W.; Močnik, G.; Drinovec, L.; Gregorič, A. Investigation of Aerosol Properties and Structures in Two Representative Meteorological Situations over the Vipava Valley Using Polarization Raman LiDAR. Atmosphere 2019, 10, 128. [CrossRef]

2. Rosu, I.-A.; Cazacu, M.-M.; Prelipceanu, O.S.; Agop, M. A Turbulence-Oriented Approach to Retrieve Various Atmospheric Parameters Using Advanced Lidar Data Processing Techniques. Atmosphere 2019, 10, 38. [CrossRef]

3. Zo, I.-S.; Shin, S.-K. A Short Note on the Potential of Utilization of Spectral AERONET-Derived Depolarization Ratios for Aerosol Classification. Atmosphere 2019, 10, 143. [CrossRef] 
4. Zheng, F.; Hou, W.; Sun, X.; Li, Z.; Hong, J.; Ma, Y.; Li, L.; Li, K.; Fan, Y.; Qiao, Y. Optimal Estimation Retrieval of Aerosol Fine-Mode Fraction from Ground-Based Sky Light Measurements. Atmosphere 2019, 10, 196. [CrossRef]

5. Xu, W.; Wang, W.; Wu, L. New Regression Method to Merge Different MODIS Aerosol Products Based on NDVI Datasets. Atmosphere 2019, 10, 303. [CrossRef]

6. De Oliveira, A.M.; Souza, C.T.; Oliveira, N.P.M.; Melo, A.K.S.; Lopes, F.J.S.; Landulfo, E.; Elbern, H.; Hoelzemann, J.J. Analysis of Atmospheric Aerosol Optical Properties in the Northeast Brazilian Atmosphere with Remote Sensing Data from MODIS and CALIOP/CALIPSO Satellites, AERONET Photometers and a Ground-Based Lidar. Atmosphere 2019, 10, 594. [CrossRef]

7. Chiliński, M.T.; Markowicz, K.M.; Zawadzka, O.; Stachlewska, I.S.; Lisok, J.; Makuch, P. Comparison of Columnar, Surface, and UAS Profiles of Absorbing Aerosol Optical Depth and Single-Scattering Albedo in South-East Poland. Atmosphere 2019, 10, 446. [CrossRef]

8. Zhang, Y.; Wang, J.; Bu, L. Analysis of a Haze Event over Nanjing, China Based on Multi-Source Data. Atmosphere 2019, 10, 338. [CrossRef]

9. Roshan, D.R.; Koc, M.; Isaifan, R.; Shahid, M.Z.; Fountoukis, C. Aerosol Optical Thickness over Large Urban Environments of the Arabian Peninsula-Speciation, Variability, and Distributions. Atmosphere 2019, 10, 228. [CrossRef]

(C) 2019 by the author. Licensee MDPI, Basel, Switzerland. This article is an open access article distributed under the terms and conditions of the Creative Commons Attribution (CC BY) license (http://creativecommons.org/licenses/by/4.0/). 